\title{
Virtual University and Gamification to Support Engineering Education
}

\author{
https://doi.org/10.3991/ijep.v10i2.13771 \\ Thrasyvoulos Tsiatsos $(\bowtie)$ \\ School of Informatics, Aristotle University of Thessaloniki, Thessaloniki, Greece \\ tsiatsos@csd.auth.gr
}

First of all I would like to thank the International Journal of Engineering Pedagogy (iJEP), as well as IGIP (International Society for Engineering Pedagogy) and IAoE (International Association of Online Engineering) for their efforts to improve engineering education and for inviting me to contribute on this field and to the debate about engineering education.

I will start on the discussion of the previous editorials, namely

- 'Five Theses on a Renaissance of Engineering Education: Skill-Driven Learning and Teaching SDLnT Editorial', iJEP, vol. 9, issue 5, (https://online-journals.org/ index.php/i-jep/issue/view/433), edited by Matthias Utesch.

- 'From Technology Enhanced Learning to Ethics and Critical Thinking as part of the Engineering Education: Skill Driven with Humanities Comprehension Editorial', iJEP, vol. 10, issue 1, https://online-journals.org/index.php/i-jep/article/view/ 12927), edited by Manuel Castro and Elio Sancristobal.

I totally agree that a forward-looking approach to engineering education is the SkillDriven Learning and Teaching (SDLnT) and, yes, Learning Technologies should play a vital role to this transformation.

I, also, agree that ethical behavior, responsibility and the alignment of our efforts on a sustainable and greener future must be a core part of us and our actions.

According to the above, it seems that we need some transformations: (a) in teaching and learning, i.e. SDLnT, (b) in Learning Technology, i.e. virtual campus and (c) in our culture, i.e. ethical behavior.

However, we should somehow orchestrate all these transformations in a very large scale. These transformations should be orchestrated in an interregional level and not only in the range of local courses or some local university program of studies.

To this direction The Education Council Conclusions of 22 May $2018^{1}$ further stressed the potential of 'European Universities' to "significantly enhance mobility and foster high quality and excellence in education and research, by strengthening the link between teaching, research and innovation and knowledge transfer, by demonstrating the benefits of multilingual learning, the recognition of qualifications and by developing joint education and research programmes and projects." They also highlighted that the European Universities "could play a flagship role in the creation of a European Education Area as a whole".

\footnotetext{
${ }^{1} \mathrm{http}: / /$ data.consilium.europa.eu/doc/document/ST-8701-2018-INIT/en/pdf
} 
'European Universities' plan to reach the above aims by gradually implementing the following key elements by $2025^{2}$ :

- Share an integrated, long term joint strategy for education with, where possible, links to research and innovation and society at large, that goes beyond any potential existing bilateral and multilateral cooperation.

- Establish a European higher education inter-university 'campus'.

- Build European knowledge creating teams ("challenge-based approach").

To the direction of the creation of 'European Universities', the EPICUR alliance 3 has been created.

EPICUR's key objective is to become a role model for a European University in boosting the mobility (be it physical, virtual, or blended) of our students, teachers, researchers and staff across the alliance's Inter-University Campus. During the pilot phase, EPICUR will adopt a step-by-step approach through testing enhanced levels of cooperation and integration on four key areas of activity: strategic policy development, innovative pedagogies, developing a platform for a virtual EPICUR campus, and connecting regional networks.

More specifically, the project will create a virtual inter-university EPICUR campus environment to broaden the opportunities for virtual mobility and the development of new courses, testing a learning platform based on gamification ${ }^{4}$.

Gamification on learning, integrated in virtual learning environments (i.e. virtual campus/virtual universities) could support SDLnT. SDLnT places the students and teachers at the centre of decisions. Through choosing which paths to follow, it results in a form of "personalized education", tailored to the specific needs of the participant and taking into account evaluation criteria which are extended beyond the traditional ones (e.g., ECTS earned, grades, certification for foreign languages) to include criteria which recognize and foster inclusiveness. For example, students who demonstrate awareness and willingness to address major societal issues, as described by many of the Sustainable Development Goals' (SDG), and students who thrive on cultural challenges or social barriers (such as non-native speakers).

Gamification will motivate students to strengthen skills and participate in learning processes. It will also support unobtrusive assessment of learning. The automatic data collection that goes on in the background when students work with rich digital environments can be applied to unobtrusive, 'stealth', assessment of their learning processes.

Of course, there are many challenges to integrate gamification in engineering education. The most important are:

- the identification of metrics and procedure for assessing the students and teachers in each discipline,

\footnotetext{
https:/ec.europa.eu/programmes/erasmus-plus/printpdf/programme-guide/part-b/three-key-actions/key-action-2/european-universities en

$3 \mathrm{https}: / /$ ec.europa.eu/education/sites/education/files/document-library-docs/european-universities-factsheet-epicur.pdf

${ }^{4}$ Muntean, Cristina Ioana. "Raising engagement in e-learning through gamification." Proc. 6th international conference on virtual learning ICVL. Vol. 1. 2011.
} 
- to be consistent with data protection regulations and the national legislations, and

- to create a virtual learning environment (i.e. Virtual University) that will support such a gamification framework.

I would like to kindly invite the readers and authors of iJEP journal, to submit their ideas of how to gamify engineering education in order to support SDLnT.

Thrasyvoulos Tsiatsos Thessaloniki, February 2020

Thrasyvoulos Tsiatsos is Assistant Professor at the School of Informatics, Aristotle University of Thessaloniki, Greece, WP4 Leader of EPICUR European University Alliance, President of IGIP Section Greece, IAOE member, IEEE member and Editor-inChief of International Journal of Interactive Mobile Technologies (iJIM). 